Review

\title{
Bioceramic Nanofibres by Electrospinning
}

\section{Rajkamal Balu $^{1}{ }^{*}$, Sivakumar Singaravelu ${ }^{2}$ and Naveen Nagiah $^{3}$}

1 Ian Wark Research Institute, University of South Australia, Mawson Lakes, Adelaide, South Australia 5095, Australia

2 Bio-Products Laboratory, Central Leather Research Institute, Adyar, Chennai 600 020, India; E-Mail: cssivakumar83@gmail.com

3 Department of Mechanical Engineering, University of Colorado, Boulder, CO 80309-0427, USA; E-Mail: naveen.nagiah@colorado.edu

* Author to whom correspondence should be addressed; E-Mail: balry011@mymail.unisa.edu.au; Tel.: +61-883-023-281.

Received: 20 July 2014; in revised form: 7 August 2014 / Accepted: 14 August 2014 /

Published: 22 August 2014

\begin{abstract}
Nanoscale three-dimensional (3D) scaffolds offer great promise for improved tissue integration and regeneration by their physical and chemical property enhancements. Electrospinning is a versatile bottom-up technique for producing porous 3D nanofibrous scaffolds that could closely mimic the structure of extracellular matrix. Much work has been committed to the development of this process through the years, and the resultant nanostructures have been subjugated to a wide range of applications in the field of bioengineering. In particular, the application of ceramic nanofibres in hard tissue engineering, such as dental and bone regeneration, is of increased research interest. This mini-review provides a brief overview of the bioceramic nanofibre scaffolds fabricated by electrospinning and highlights some of the significant process developments over recent years with their probable future trends and potential applications as biomedical implants.
\end{abstract}

Keywords: bioceramics; electrospinning; nanofibres; 3D scaffold; tissue engineering

\section{Introduction}

Ceramic materials employed within the body are generally termed bioceramics, which fall into the classifications of being bioinert, bioresorbable and bioactive based on the properties of remaining 
unchanged, dissolving or actively taking part in a physiological process. Materials classified as bioceramics include alumina, zirconia, calcium phosphates, titania, silica-based glasses or glass ceramics and pyrolytic carbons [1]. Various forms of bioceramics have been fabricated based on the need and applications, comprised of microspheres, thin layer coating on implants, porous networks, composites with a polymer component and large well-polished surfaces [2]. The properties of solids are altered with great reductions in particle size ranging to the scale of nanometres, which does not easily come into play when going from macro- to micro-dimensions. Ceramic structures at the nanometre range have been proven to have improved properties and characteristics that differ from their bulk, allowing for opportunities in novel technological applications [3]. Top-down and bottom-up approaches are the two major routes to obtain ceramic nanostructures. Ceramic nanofibres, having advantages, including a very high surface-to-volume and aspect ratio, over other forms, can be processed by a number of techniques, including template-assisted synthesis [4], self-assembly [5] and electrospinning [6].

Electrospinning is a versatile bottom-up technique that was introduced in the early 1930s [7]. It has gained increased interest since 2000 for its continuous one-dimensional nanofibre production possibility. During the past decade, a large number of research activities involving electrospinning increased, leading to the development of mass-production, innovative compositions and a large variety of applications spanning many industrial sectors [8]. However, electrospinning of ceramic nanofibres, especially bioceramics, offers challenges to the process and control of the orientation. This paper reviews significant reports on the electrospinning of various bioceramic nanofibres, research developments and their potential applications in the biomedical field.

\section{Electrospinning Bioceramic Nanofibres}

For electrospun ceramic nanofibrous scaffolds in biomedical applications, the biological properties, such as biocompatibility, biodegradability and specific cell interactions, are largely determined by the materials' properties and nature. Electrospun scaffolds can be tailored with desired new functions by selecting a suitable material or composite and by adjusting the component ratio, fibre diameter and morphology through process parameters. In the process of electrospinning, a high electrostatic voltage is imposed on a drop of solution held by its surface tension at the end of a capillary, leading to distortion of the liquid into a conical jet (known as the Taylor cone), ejecting fibres $[9,10]$. Once the voltage exceeds a critical value, the electrostatic force overcomes the solution surface tension, and a stable liquid jet is ejected from the cone tip. The solvent evaporates as the jet travels through the air, leaving behind ultra-fine fibres with a high surface-to-volume ratio collected on an electrically-grounded target $[11,12]$.

With two types of electrospinning, namely melt spinning and wet spinning, being practiced, the latter is the most commonly used. In melt spinning, the material is melted by applying external heat to form a melt to spin, whereas in wet spinning, the component is dissolved in a suitable solvent to form a spinnable solution, which is then subjected to high electrostatic voltage $[13,14]$. As ceramics have a high melting point, they are mostly electrospun by the wet method as a sol-gel or composites with a polymer in the form of solution [3]. A typical wet electrospinning setup is shown in Figure 1. In general, ceramic nanofibres are produced by electrospinning ceramic precursors or nanoparticles along 
with polymer followed by calcination at higher temperatures to remove polymer residues. However, there are also reports on the fabrication of ceramic nanofibres from ceramic sols in the absence of polymers [15-17].

Figure 1. A typical wet electrospinning setup.

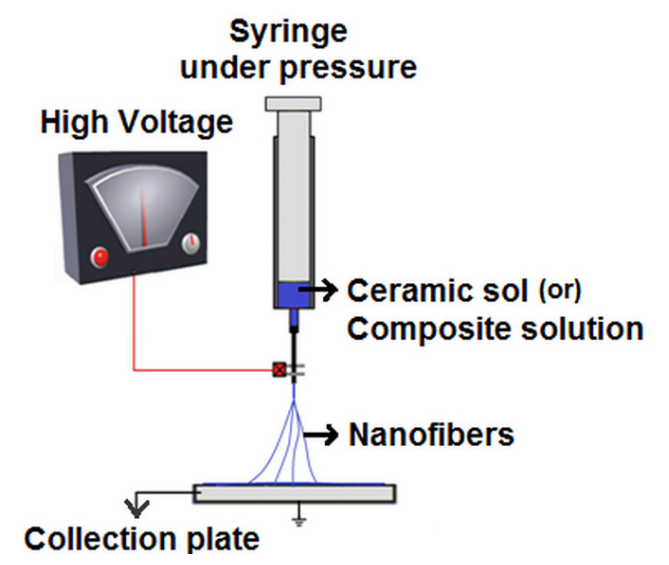

\subsection{Alumina Nanofibres}

Alumina $\left(\mathrm{Al}_{2} \mathrm{O}_{3}\right)$ is a bioinert ceramic with the characteristics of high abrasion resistance and chemical inertness. The biocompatibility of alumina has made it clinically reliable for more than 30 years [18]. $\mathrm{Al}_{2} \mathrm{O}_{3}$, being used in both dental and orthopaedic applications, has shown increased osteoblast adhesion in nanofibre form compared to nanosphere and conventional alumina, with either nanometre- or micrometre-sized grains, which is promising as a potential substitute for bone tissue implants [19]. Azad et al. [20] fabricated transparent $\alpha-\mathrm{Al}_{2} \mathrm{O}_{3}$ nanofibres of high structural quality by electrospinning composite sol made of high purity aluminium 2,4-pentanedionate and polyvinylpyrrolidone (PVP). The author performed the conceived temperature-time-heating rate profile calcination at $1000-1500{ }^{\circ} \mathrm{C}$ to understand the pathway of phase evolution in the ultimate ceramic product with the scope of the retention of the fibrillar artefacts. Raman studies of fired fibres were shown to be identical to those registered for commercial $\alpha$-alumina powder with confirmation of the phase evolved to be $\alpha$-alumina using a selected area electron diffraction (SAED) pattern. Panda et al. [21] reported electrospinning of $\mathrm{Al}_{2} \mathrm{O}_{3}$ nanofibres using aluminium acetate and aluminium nitrate in combination with polyvinyl alcohol (PVA) and polyethylene oxide (PEO). The authors demonstrated that electrospinning of both PVA and PEO was possible and was smooth in the case of the aluminium acetate precursor, whereas in the case of the aluminium nitrate precursor, the resulting nanofibres were reported to be highly hygroscopic, due to the presence of nitrate anions with difficulty in collection due to the strong repulsion. Through a similar approach, Tuttle et al. [22] fabricated and characterized $\mathrm{Al}_{2} \mathrm{O}_{3}$ nanofibres using boric acid-stabilized aluminium acetate and PVP. The authors measured a wide range of electrospinning conditions and characterization techniques to determine the types of bulk and surface characteristics that can be attained with these fibres after calcinations (Figure 2a,b).

In contrast, Lamastra et al. [23] presented electrospinning of PVA solution containing dispersed alumina nanoparticles (20 $\mathrm{nm}$ average size). The authors used nanofiller content ranging between 2 and $9 \mathrm{wt} \%$, and the average fibre size was reported as $600 \mathrm{~nm}$ with $\mathrm{Al}_{2} \mathrm{O}_{3}$ nano- and/or 
sub-micrometric agglomerates observed on and/or inside the PVA fibres. Yu et al. [24] examined the growth-related microstructures and the length-to-diameter ratio of single-crystal-type $\alpha-\mathrm{Al}_{2} \mathrm{O}_{3}$ electrospun nanofibres using HR-TEM. The author described that single-crystal $\alpha-\mathrm{Al}_{2} \mathrm{O}_{3}$ nanofibres were found to form via the coalescence of well-elongated $\alpha-\mathrm{Al}_{2} \mathrm{O}_{3}$ colonies growing in the (110) or (112) directions. The length-to-diameter ratio of each colony was reported to follow the thermodynamic requirement that exists with a size ratio limit for the length and diameter of each $\alpha-\mathrm{Al}_{2} \mathrm{O}_{3}$ colony. Recently, Yu et al. [25] fabricated $\mathrm{Al}_{2} \mathrm{O}_{3}$ electrospun nanofibres from a novel solution containing water-insoluble polyacrylonitrile (PAN), non-aqueous N,N-dimethylformamide (DMF) and aluminium 2,4-pentanedionate, in which the mass ratio of aluminium to PAN of 1:1 was obtained. The author also reported that increasing the ceramic nanoparticle content decreased the crystallinity of fibres. With respect to hard tissue engineering applications, studies by Price et al. [19,26] revealed increased osteoblast function on nanofibre $\mathrm{Al}_{2} \mathrm{O}_{3}$ compared to other forms (Figure 2c) with possible explanations for such enhanced behaviour attributed to chemistry, the crystalline phase and topography, suggesting that it may be an ideal material for use in orthopaedic and dental applications.

Figure 2. SEM images of (a) as-spun aluminium acetate/polyvinylpyrrolidone (PVP) fibres; (b) electrospun fibres after $1200{ }^{\circ} \mathrm{C}$ annealing [22] (reproduced with permission from Elsevier, Copyright 2006); and (c) osteoblast cell density under standard cell culture conditions determined on various alumina substrates. All data shown are the mean \pm SEM $(=3) .{ }^{*} p<0.05$ compared with all other material formulations; ${ }^{+} p<0.05$ compared with conventional spherical alumina; ${ }^{*} p<0.05$ compared with either reference material (glass and titanium) [26] (reproduced with permission from Wiley, Copyright 2003).

(a)

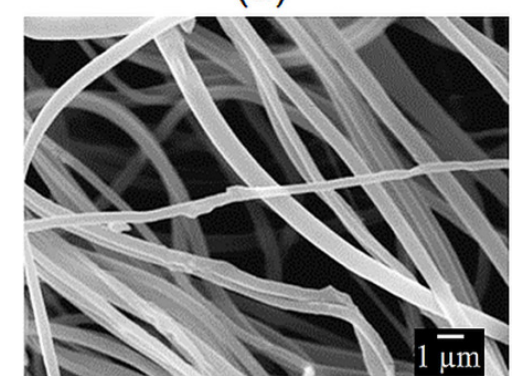

(b)

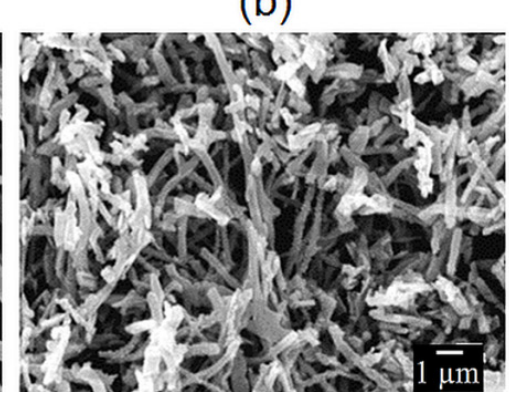

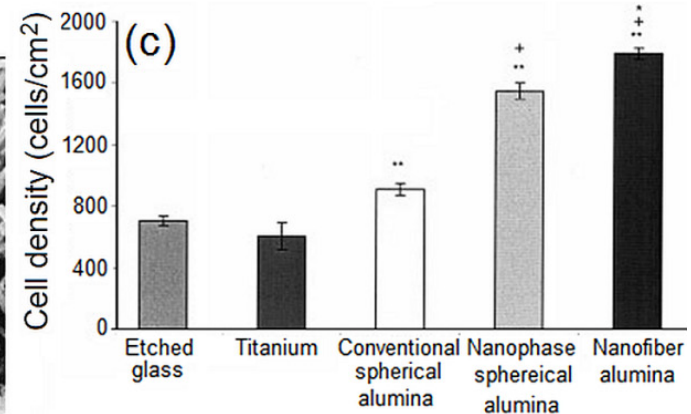

\subsection{Zirconia Nanofibres}

Zirconia $\left(\mathrm{ZrO}_{2}\right)$, introduced in 1985 as an alternative material to alumina, is a bioinert bioceramic that has gained its application in total hip replacement for its high mechanical strength and fracture toughness [1]. Microscopic studies in animals have demonstrated that $\mathrm{ZrO}_{2}$ implants possess good biocompatibility and direct bone apposition to the implant [27]. Shao et al. [28] demonstrated the electrospinning of a sol comprising zirconia oxychloride and PVA followed by calcinations of the fibres at $800{ }^{\circ} \mathrm{C} . \mathrm{ZrO}_{2}$ nanofibres with diameters of 50-200 nm were reported after calcinations [28]. Dharmaraj et al. [29] fabricated $\mathrm{ZrO}_{2}$ nanofibres of 200-nm diameter upon calcination of the zirconium oxide/poly(vinyl acetate) (PVAc) composite nanofibres prepared by sol-gel processing and electrospinning. The author demonstrated that calcination at $500{ }^{\circ} \mathrm{C}$ and $750{ }^{\circ} \mathrm{C}$ showed the presence of a tetragonal phase along with some traces of monoclinic zirconium oxide and calcination at 
$1000{ }^{\circ} \mathrm{C}$ with the monoclinic phase identified. In contrast, Lamastra et al. [23] demonstrated electrospinning of a solution comprising $\mathrm{ZrO}_{2}$ nanoparticle (20 $\mathrm{nm}$ average size) dispersed in PVA solution of $8 \mathrm{wt} \%$. The average fibre size was reported as $600 \mathrm{~nm}$ with a homogeneous distribution of $\mathrm{ZrO}_{2}$ in polymer mats (Figure 3a). $\mathrm{ZrO}_{2}$ and zirconium nitride ( $\mathrm{ZrN}$ )-coated biocompatible leads showing enhanced thrombogenicity, biocompatibility, blood compatibility and corrosion-resistance were patented earlier by Davidson et al. [30]. With $\mathrm{ZrN}$ shown to be biocompatible, Li et al. [31] successfully fabricated a $\mathrm{ZrN}$ nanofibre preparation by carbothermal reduction and nitridation of electrospun PVP/zirconium oxychloride composite fibres, whose fibre structure was kept by the connection of irregular fine particles, and the diameter of crystalline $\mathrm{ZrN}$ was reported in the range of 100-500 nm (Figure 3b). Ahmad et al. [32] earlier showed that yttrium partially-stabilized zirconium dioxide posts as an approach to restoring coronally compromised non-vital teeth, and Azad et al. [33] reported the fabrication of phase pure yttria-stabilized zirconia nanofibres by electrospinning, investigating the structural and microstructural artefacts of the spun fibres. Recently, Li et al. [34] fabricated hollow fibres of yttria-stabilized zirconia (8YSZ) by calcination of electrospun composite fibres from sol comprised of zirconium oxychloride, yttrium nitrate and PVP, where the fibres were reported to be made of polycrystalline tetragonal phase $\mathrm{ZrO}_{2}$ (Figure 3c).

Figure 3. $\mathrm{SEM}$ images of (a) electrospun $\mathrm{PVA} / \mathrm{ZrO}_{2}-\mathrm{H}$ nanohybrid mats (inset: energy-dispersive X-ray spectrum) [23] (reproduced with permission from Elsevier, Copyright 2008); (b) $\mathrm{ZrN}$ fibres after heating treatment at $1600{ }^{\circ} \mathrm{C}$ [31] (reproduced with permission from Elsevier, Copyright 2008); and (c) 8YSZ hollow fibres calcined at $1000{ }^{\circ} \mathrm{C}[34]$ (reproduced with permission from Elsevier, Copyright 2008).

(a)

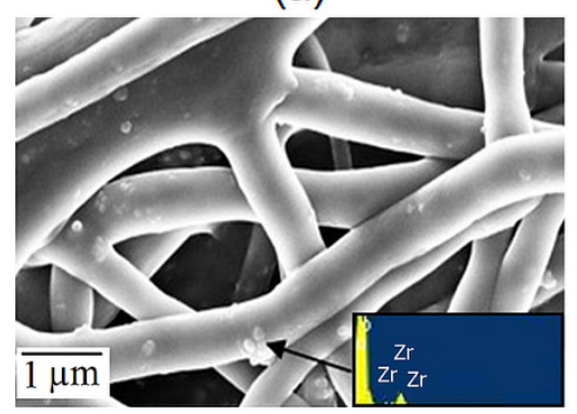

(b)

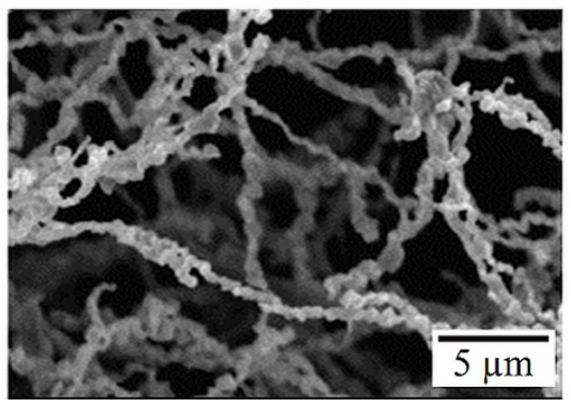

(c)

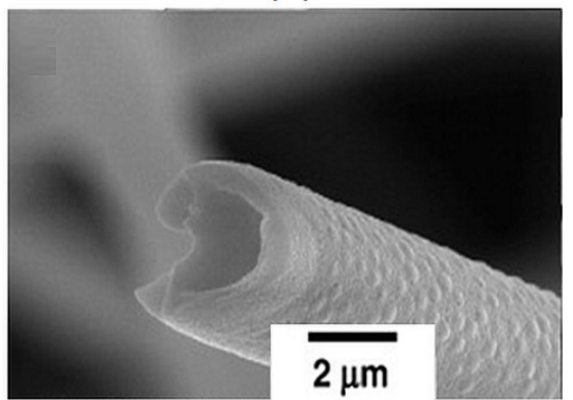

On the other hand, Kotha et al. [35] reported reinforcement of bone cements using $\mathrm{ZrO}_{2}$ fibres, supporting the potential applications of zirconia in orthopaedic applications. Li et al. [36] studied the phase transformation and morphological evolution of electrospun $\mathrm{ZrO}_{2}$ nanofibres during thermal annealing and reported that at different thermal cycles, the monoclinic-to-tetragonal transformation temperatures remained virtually unchanged, while the reverse transition temperatures systematically shifted from 924.9 to $978.6{ }^{\circ} \mathrm{C}$ with the progress of thermal cycles. Recently, Qin et al. [37] fabricated $\mathrm{ZrO}_{2}$ nanofibres with different morphologies, such as porous or compact fibres, in addition to the observed crystalline structure. Interestingly, $\mathrm{Xu}$ et al. [38] successfully demonstrated dense zirconia-yttria (ZY), zirconia-silica (ZS) and zirconia-yttria-silica (ZYS) nanofibres as reinforcing elements for dental composites. 


\subsection{Titania Nanofibres}

Titanium oxide $\left(\mathrm{TiO}_{2}\right)$ and titanium alloys are superior to many biomedical materials, such as pyrolytic carbon, stainless steel, etc., for their mechanical properties and biocompatibility. $\mathrm{TiO}_{2}$ is a non-toxic, multi-faceted bioceramic, widely studied for its excellent biocompatibility [39,40]. Lee et al. [41] reported $\mathrm{TiO}_{2} / \mathrm{PVP}$ nanocomposite nanofibres with average diameters of $\sim 53$ and $\sim 109 \mathrm{~nm}$ electrospun via a sol-gel prepared from Ti(IV)-isopropoxide (TiP) precursor (Figure 4a), whereas Son et al. [15] reported electrospinning of ultrafine $\mathrm{TiO}_{2}$ fibres in the absence of polymer additives with the formation of pure anatase titania fibres at low temperature. Interestingly, Son et al. [15] used nitric acid as the acid catalyst for the hydrolysis and polycondensation of TiP titanium. The surface of the $\mathrm{TiO}_{2}$ fibres in as-spun form was shown to be smooth and uniform, whereas the fibres obtained after calcination at $1300{ }^{\circ} \mathrm{C}$ were reported to have wavy surfaces [15]. Lim et al. [42] successfully immobilized $\mathrm{TiO}_{2}$ nanofibres on titanium plates by electrospinning of sol comprising PVP and TiP for implant applications. On the other hand, Yuh et al. [43] reported barium titanate $\left(\mathrm{BaTiO}_{3}\right)$ nanofibres via electrospinning, which was supposed to have other applications by that time (Figure $4 \mathrm{~b}$ ). $\mathrm{BaTiO}_{3}$ nanofibres with a perovskite structure were obtained after annealing at $750{ }^{\circ} \mathrm{C}$ for $1 \mathrm{~h}$, and the typical fibre morphology reported was 80-190 nm [43]. Later, Li et al. [44] reported the biocompatibility of $\mathrm{BaTiO}_{3}$ to have enhanced effects on the bioactivity of the nano-titania ceramics, which made the osteoblasts proliferate faster on the nano-titania ceramics in cell culture experiments. The author also suggested that this might be a potential way to prepare bioactive nano- $\mathrm{TiO}_{2}$ ceramics with biomechanical compatibility using $\mathrm{BaTiO}_{3}$ as a crystal growth inhibitor.

With magnesium titanate identified to be osteo-inductive [45], Dharmaraj et al. [46] demonstrated phase pure magnesium titanate nanofibres of $200-400 \mathrm{~nm}$ in diameter with preparation at low temperatures for the first time by electrospinning sol-gel prepared from magnesium ethoxide, TiP and PVAc. On the other hand, Lee et al. [47] fabricated silicon dioxide $\left(\mathrm{SiO}_{2}\right) / \mathrm{TiO}_{2}$ composite fibres by sol-gel reaction and electrospinning. This silica-doped titania $\left(\mathrm{SiO}_{2} / \mathrm{TiO}_{2}\right)$ was later reported to be biocompatible with potential implant applications [48]. Dharmaraj et al. [49] reported the preparation and characterization of nickel-titanate $\left(\mathrm{NiTiO}_{3}\right)$ nanofibres with diameters in the range of $150-200 \mathrm{~nm}$, for the first time using electrospun nickel titanate/PVAc composites as precursors and through calcination treatment. The author reported the crystalline phases present in the fibres after calcination treatment at different temperatures using X-ray diffraction analysis (XRD) (Figure 4c). The biocompatibility of $\mathrm{NiTiO}_{3}$ was later discussed by Bansiddhi et al. [50], accounting for its bioactivity in biomedical applications.

In another context, Bahadur et al. [51] demonstrated the synthesis of hydroxyapatite crystals on electrospun $\mathrm{TiO}_{2}$ nanofibres. The authors verified the chemical treatment of $\mathrm{TiO}_{2}$ nanofibres by immersion in sodium hydroxide solution followed by calcination, $\mathrm{HCl}$ treatment and, finally, soaking in simulated body fluid (SBF) for various time intervals. These ceramic nanocomposite have special interest for biomedical applications, such as in dental and bone implants. Interestingly, a biological evaluation of the antimicrobial activity of electrospun $\mathrm{Zn}$-doped titania nanofibres was performed by Anna et al. [52]. The authors reported the lowest concentration of $\mathrm{Zn}$-doped titania nanofibre solution inhibiting the growth of $S$. aureus ATCC 29231 and E. coli ATCC 52922 strains to be 0.4 and $1.6 \mu \mathrm{g} / \mathrm{mL}$. A similar study was also performed by Hassan et al. [53], who reported the lowest 
concentration of titania nanorod solution inhibiting the growth of a microbial strain with $5 \mu \mathrm{g} / \mathrm{mL}$ for a wide range of pathogens tested. Furthermore, the morphology and osteogenic potentials of $\mathrm{TiO}_{2}$-based electrospun nanofibres were recently studied by Wang et al. [54]. With $\mathrm{TiO}_{2}$ occurring in most common phases of anatase and rutile, Kiran et al. [55] recently studied the effects of the morphology and crystalline phase of electrospun $\mathrm{TiO}_{2}$ nanofibres on osteoblast cell response. Interestingly, the authors reported the rutile phase of electrospun $\mathrm{TiO}_{2}$ nanofibres to be relatively more favourable for osteoblast cell attachment and mineralization.

Figure 4. TEM image of (a) $\mathrm{TiO}_{2}$ nanofibres [41] (reproduced with permission from Elsevier, Copyright 2005); and (b) $\mathrm{BaTiO}_{3}$ nanofibres (upper inset: high resolution image showing lattice fringes; lower inset: convergent beam electron diffraction pattern) [43] (reproduced with permission from Elsevier, Copyright 2005); (c) XRD patterns of $\mathrm{NiTiO}_{3}$ fibres (label code a: as-prepared composite fibres; b: fibres calcined at $873 \mathrm{~K}$; c: fibres calcined at $1073 \mathrm{~K}$; d fibres calcined at $1173 \mathrm{~K}$; and e fibres calcined at $1273 \mathrm{~K}$ ) [49] (reproduced with permission from Elsevier, Copyright 2004).
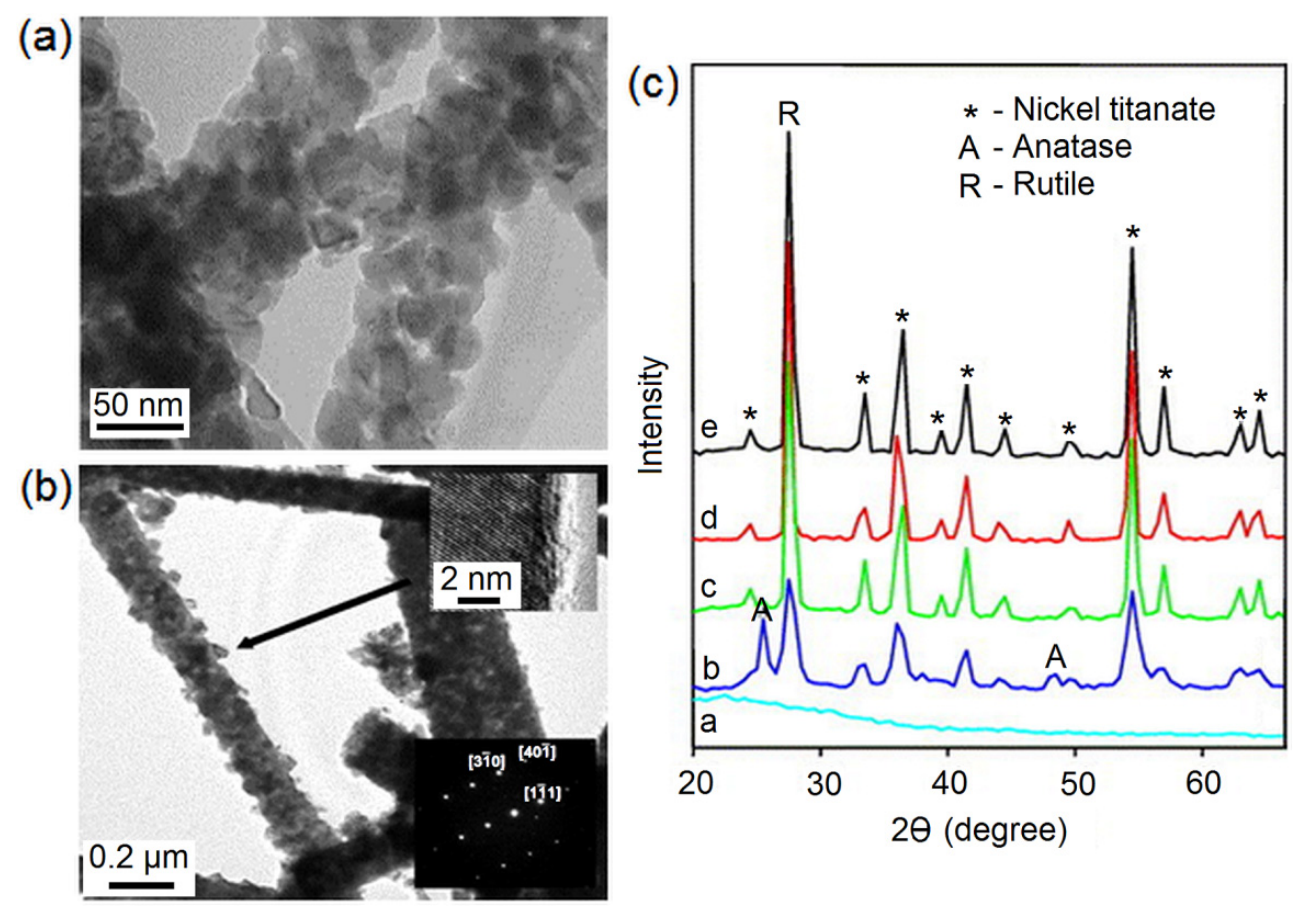

\subsection{Pyrolytic Carbon Nanofibres}

Carbon exists in a variety of forms, including vitreous carbon and pyrolytic carbon. Intrinsic brittleness and low tensile strength limit its use in major load bearing applications. The key properties of pyrolytic carbon, such as biocompatibility, thrombo-resistant, good durability, wear resistance and strength, has made it applicable in the field of biomedical engineering [56]. Santiago-Aviles et al. [57] reported early electrospinning of polyacrylonitrile (PAN)-derived carbon fibres. The biocompatibility of filamentous carbon fibres was studied by Zimmerman et al. [58] and reported to be non-corrodible, bringing about no immunological response in vivo. In addition, pyrolytic carbon is also suited to small orthopaedic joints, such as fingers and spinal inserts. Zussman et al. [59] demonstrated electrospinning of PAN-derived carbon fibres and reported that the carbonized nanofibres showed the $\mathrm{C}$ atoms to be 
partitioned into $\sim 80 \% \mathrm{sp}^{2}$ bonds and $\sim 20 \% \mathrm{sp}^{3}$ bonds, which agrees with the observed structural disorder in the fibres (Figure 5a). An electrospinning process using different PAN/DMF concentrations was demonstrated by Gomes et al. [60]. The authors demonstrated that the viscosity and applied voltage strongly affected the shape, length and morphology of the fibres. Kima et al. [61] demonstrated the ability to fabricate ultra-fine carbon fibres through electrospinning of the polymer blends of PAN and polyamic acid (PAA) with subsequent thermal treatment. Interestingly, the author derived a close correlation between the fibre diameter developed in the spinning process and the physical properties of the carbonized fibres; where the smaller diameter fibres were reported to give rise to the higher crystallinity of the single carbonized fibre and the mechanical strength of the carbonized fibre web.

Figure 5. (a) SEM image of the fracture (during bath ultrasonication) surface of carbonized polyacrylonitrile (PAN) fibres [59] (reproduced with permission from Elsevier, Copyright 2005); (b) TEM image of nanocomposite fibrils showing a uniform distribution, no agglomeration and excellent SWNT alignment in a PAN fibre with a diameter of about $50 \mathrm{~nm}$ [62] (reproduced with permission from Wiley, Copyright 2003); (c) SEM image of L929 mouse fibroblasts growing on an MWCNT-based network after seven days [63] (reproduced with permission from American Chemical Society, Copyright 2004).

(a)

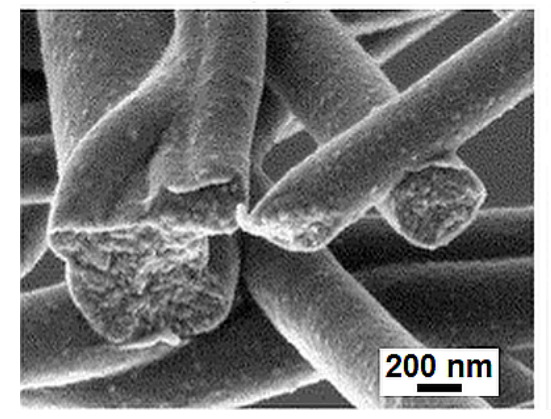

(b)

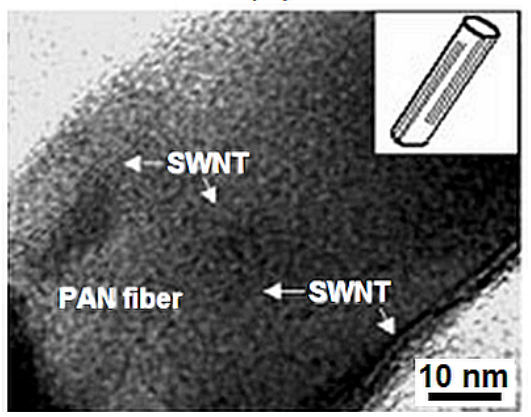

(c)

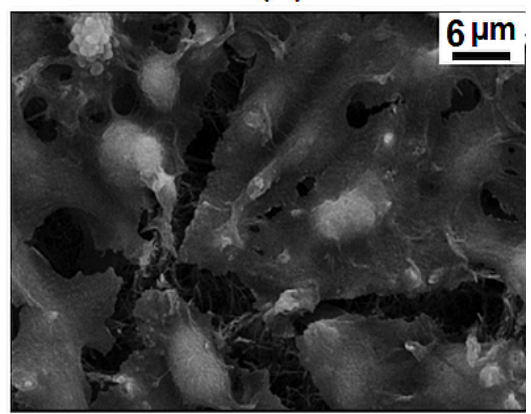

On the other hand, Ko et al. [62] demonstrated co-electrospinning of single-walled carbon nanotube (SWCNT)-filled nanofibre yarn (Figure 5b), whereas, Lam et al. [64] demonstrated electrospinning of both SWCNT and multi-walled carbon nanotube (MWCNT)-filled nanofibres. With the biocompatibility of carbon nanotubes (CNTs) being questioned, Duarte et al. [63] demonstrated thin film networks of MWCNTs and their potential in biomedical applications by extensive growth, spreading and adhesion of the common mouse fibroblast cell line, L929, on them (Figure 5c). Further, Smart et al. [65] discussed the biocompatibility of carbon nanotubes, reporting that chemically-functionalized CNTs enhanced for drug delivery and have not demonstrated any toxicity. Moreover, Yeo et al. [66] has discussed the biocompatibility of various electrospun carbon nanotube polymer composites, as well as their characteristics and applications elsewhere. Zhang et al. [67] fabricated, by electrospinning, uniaxially-aligned carbon nanotube composite nanofibres with a diameter of $\sim 100 \mathrm{~nm}$ using a collector consisting of two electrodes, as well as a slowly rotating drum. Wan et al. [68] successfully fabricated MWCNT-filled PAN fibres by electrospinning via both conventional and vibrational electrospinning. The authors reported that CNTs were aggregated heavily in the fibres obtained by traditional electrospinning, while CNTs were well distributed and aligned in 
PAN fibres obtained by vibration-electrospinning. A whole new class of bioactive carbon nanofibres has been created for biological applications, and the applications in regenerative medicine are reviewed elsewhere [69,70]. Recently, Volpato et al. [71] studied the tuneable morphological and mechanical properties of electrospun nanofibres composed of aligned fibres of polyamide 6 (PA6) and carboxyl-functionalized MWCNT. The authors reported that the proliferation and activation of microglial MG63 osteoblast cell lines were enhanced due to surface modification caused by the filler addition compared to the pristine PA6 networks.

\subsection{Calcium Phosphate Ceramic Nanofibres}

It has been known for years that calcium phosphate ceramics are used for bone tissue augmenting and replacement. There are several calcium phosphate ceramics that are considered to be biocompatible, including $\alpha$-tricalcium phosphate $(\alpha$-TCP), $\beta$-tricalcium phosphate $(\beta$-TCP), tetracalcium phosphate $\left(\mathrm{Ca}_{4} \mathrm{P}_{2} \mathrm{O}_{9}\right)$ and hydroxyapatite $(\mathrm{HAp})\left(\mathrm{Ca}_{10}\left(\mathrm{PO}_{4}\right)_{6}(\mathrm{OH})_{2}\right)$, of which $\mathrm{HAp}$ is the most widely studied bioceramic, as it is thermodynamically stable at physiological $\mathrm{pH}$ and actively takes part in bone bonding. The $\mathrm{Ca} / \mathrm{P}$ ratio of HAp is 1.67 equivalents to that of bone and is stable in body fluids [2]. Ito et al. [72] reported solution-mediated mineralization of HAp on biodegradable polymer nanofibres where the surface mineralization of HAp contributed to the bioactivity of the polymer fibre mats. Venugopal et al. [73] demonstrated nano-HAp (nHAp) powder-dispersed biodegradable collagen-polycaprolactone composite polymers ( $\mathrm{PCL} / \mathrm{nHAp} / \mathrm{Col}$ ) of a diameter ranging from 60 to $600 \mathrm{~nm}$ by electrospinning. The authors reported that PCL provided mechanical stability, collagen-supported cell proliferation and nHAp for the mineralization of osteoblasts for bone regeneration. Mei et al. [74] reported electrospinning of nHAp sol prepared from triethyl phosphite precursor and PVP as a polymer component. On the other hand, Li et al. [75] demonstrated conjugate electrospinning of poly(L-lactide)(PLLA)/nano- $\beta$-TCP composite nanofibres, where the authors used two spinnerets with opposite polarity. The effect of the process and solution parameters on the fibre morphology were demonstrated, and the nanofibres were reported to have a rough surface, which is attributed to the dispersion of TCP nanoparticles on the surface of the composite nanofibres [75].

Interestingly, Erisken et al. [76] fabricated functionally-graded electrospun polycaprolactone and $\beta$-TCP nanocomposites for tissue engineering applications by hybrid twin-screw extrusion/electrospinning carried out for spinning fibres of a diameter ranging from 200-2000 nm. Teng et al. [77] demonstrated $30 \mathrm{wt} \%$ collagen-HAp composite sol preparation by a modified procedure followed by electrospinning of the sol, where the modified procedure demonstrated a higher efficiency in preparing uniform inorganic/organic composite nanofibres than the conventional method (Figure 6a). Similarly, Guan et al. [78] reported electrospinning of poly(3-hydroxybutyrate) (PHB)-based fibrous scaffolds containing $10 \mathrm{wt} \% \mathrm{nHAp}$ that exhibited much better support for the attachment, proliferation and differentiation of rat bone marrow stromal cells (BMSCs) than pure PHB scaffolds. It was also reported that, compared with the pure PHB fibres, which were smooth and uniform, the surfaces of the nHAp/PHB composite fibres were rougher, as nHAp nanoparticle protruded from the surface layer of the composite fibres. Zhang et al. [79] presented a two-step approach combining the in situ co-precipitation synthesis route with the electrospinning process to prepare a novel type of biomimetic nanocomposite nanofibres of HAp/chitosan. The author 
demonstrated that the incorporation of HAp nanoparticles into chitosan (CTS) nanofibrous scaffolds led to significant bone formation-oriented outcomes compared to that of the pure electrospun CTS scaffolds. On the contrary, Liao et al. [80] and Yang et al. [81] demonstrated solution-mediated mineralization of nHAp on biodegradable polymer nanofibres, such as collagen, poly(lactic-co-glycolic acid) (PLGA) and PCL (Figure 6b). The authors reported that the surface mineralization of HAp contributes to the bioactivity of the polymer fibre mats with a decrease in the contact angle (Figure 6c).

Figure 6. (a) TEM image of the collagen-30 wt $\%$ HAp composite fibres at high magnifications. The inset shows the selected area diffraction (SAD) pattern of the fibres [77] (reproduced with permission from Elsevier, Copyright 2008); (b) SEM micrograph showing the surface of the electrospun polycaprolactone (PCL) scaffolds after coating with simulated body fluid (SBF; 10×) for $2 \mathrm{~h}$; and (c) contact angle measurements on a pristine electrospun PCL mat and electrospun PCL scaffolds after coating with SBF10 for $2 \mathrm{~h}$ [81] (reproduced with permission from Elsevier, Copyright 2008); (d) single-phase hydroxyapatite (HAp) fabrics (film and tube) prepared by calcination of HAp/PVP composite nanofibres as the precursor [82] (reproduced with permission from Elsevier, Copyright 2010).

(a)

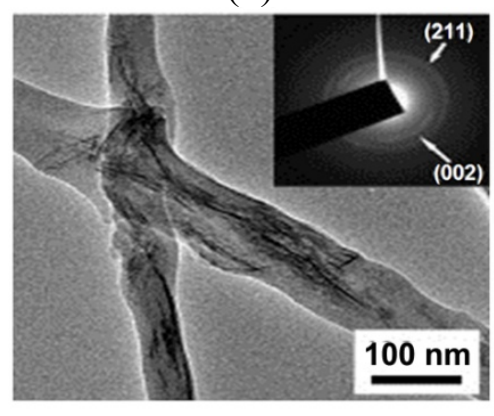

Sample

untreated PCL film (b)

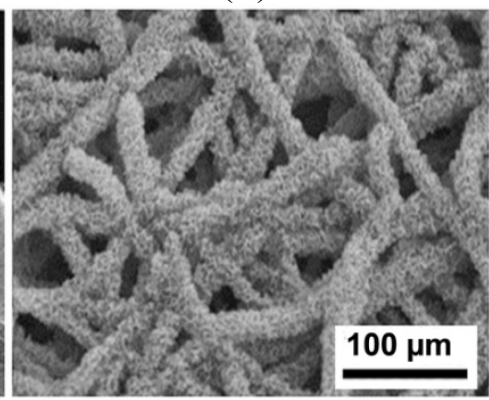

(d) (c)

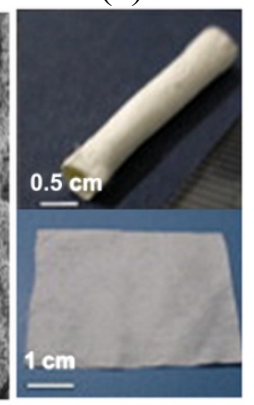

$1 \mathrm{~cm}$

\section{(d)}

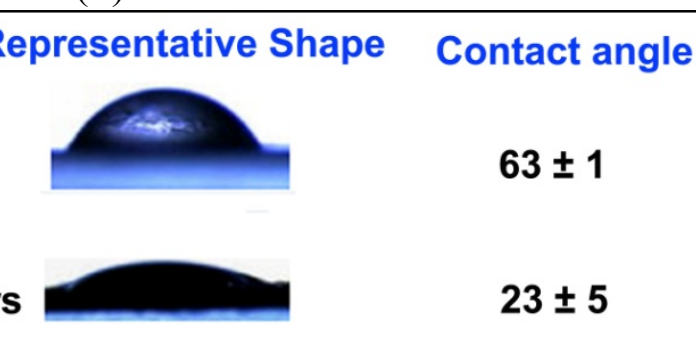

Interestingly, $\mathrm{Yu}$ et al. [83] showed the mineralization of nanocrystalline apatite on poly(3-hydroxybutyrate-co-3-hydroxyvalerate) (PHBV) through a series of solution-mediated biomimetic processes on the surface of PCL nanofibre scaffolds. The surface-mineralized PCL nanofibres were demonstrated to support the adhesion and growth of rat bone-marrow stromal cells (rBMSCs) and to stimulate their differentiation into an osteogenic lineage, showing a potential matrix for skeletal tissue regeneration [83]. Jose et al. [84] fabricated aligned PLGA/HAp nanofibrous composite scaffolds by electrospinning and demonstrated in vivo biodegradation of the electrospun scaffolds. Biansco et al. [85] demonstrated electrospinning of calcium-deficient nHAp with PCL 
followed by mechanical characterization and biocompatibility using mouse fibroblast. Recently, Chen et al. [82] demonstrated sintered HAp nanofibres (Figure 6d) from nanoparticles by an electrospinning system comprising nHAp particles and PVP. The fibres were calcined to $600{ }^{\circ} \mathrm{C}$ for $6 \mathrm{~h}$ to get a continuous fibre structure shown to be biocompatible with mesenchymal stem cells by electron microscopy. However, the mechanical properties of HAp have been reported to be unsuitable for load-bearing applications, such as orthopaedics; therefore, it is mostly used as a coating on materials, such as titanium and titanium alloy nanofibres, where it can contribute its 'bioactive' properties, while the metallic component bears the load [82]. Fascinatingly, Wei et al. [86] reported a promising novel bone tissue engineering biocomposite scaffold material made of electrospun silk fibroin/nHAp by means of an effective calcium and phosphate (Ca-P) alternate soaking method within several minutes without any pre-treatment. With the osteoblastic-like cell line MC3T3-E1 (derived from Mus musculus (mouse) calvaria) functionalities, such as alkaline phosphatase (ALP) activity, shown to ameliorate mineralized nanofibre, the silk/nHA biocomposite scaffold material could be a promising biomaterial for bone tissue engineering [86]. Very recently, Song et al. [87] demonstrated tuned morphological electrospun HAp nanofibres by electrospinning and sol-gel showing that HAp nanofibres are even and well-crystallized, and the $\mathrm{pH}$ is crucial for producing HAp nanofibres. The authors reported that with the change of $\mathrm{pH}$ from 4 to 9 , nanofibres grow densely along the (210) plane and become compact, while the surface area, pore volume and pore size decrease correspondingly.

\subsection{Bioactive Glass Nanofibres}

Bioactive glasses are a group of surface-reactive biocompatible glass-ceramics first developed by Larry Hench and colleagues at the University of Florida in the late 1960s [88]. Kim et al. [89] reported the first electrospinning of bioactive glass nanofibres with variable diameters using a sol-gel precursor of the composition $70 \mathrm{SiO}_{2} \cdot 25 \mathrm{CaO} \cdot 5 \mathrm{P}_{2} \mathrm{O}_{5}$ prepared under appropriate conditions (Figure $7 \mathrm{a}$ ). The authors reported that the nanofibres demonstrated excellent bioactivity and osteogenic potential in vitro by a bioactivity test and cellular response assay. Furthermore the authors developed a novel nanocomposite biomaterial consisting of bioactive glass nanofibre (BGNF) and collagen for bone regenerative medicine from a sol-gel with a bioactive composition $\left(58 \mathrm{SiO}_{2} \cdot 38 \mathrm{CaO} \cdot 4 \mathrm{P}_{2} \mathrm{O}_{5}\right)$ by electrospinning (Figure 7b) [90]. The average fibre diameter was reported to be $\sim 320 \mathrm{~nm}$, and the nanocomposite exhibited an active induction of apatite minerals on its surface under simulated body fluid conditions, showing excellent bioactivity in vitro. Further, the authors also demonstrated the bioactivity and osteoblast responses of a novel biomedical nanocomposite of bioactive glass $\left(58 \mathrm{SiO}_{2} \cdot 38 \mathrm{CaO} \cdot 4 \mathrm{P}_{2} \mathrm{O}_{5}\right)$ nanofibre-filled poly(lactic acid). The electrospun nanofibre reported had a diameter of $320 \mathrm{~nm}$ on average and subsequently was combined with PLA solution under adjusted processing conditions. The reported nanofibre-PLA exhibited a typical nanocomposite structure, wherein the glass nanofibres were uniformly dispersed in the PLA matrix [91]. Lee et al. [92] demonstrated improved bioactivity of PCL membrane electrospun with the addition of nanofibrous bioactive glass $\left(70 \mathrm{SiO}_{2} \cdot 25 \mathrm{CaO} \cdot 5 \mathrm{P}_{2} \mathrm{O}_{5}\right)$. The bioactivity and osteoblastic responses of the nanocomposite membrane was reported with a higher level of growth than on the pure PCL membrane. Yi et al. [93] effectively prepared sol-gel-derived mesoporous bioactive glass $\left(80 \mathrm{SiO}_{2} \cdot 15 \mathrm{CaO} \cdot 5 \mathrm{P}_{2} \mathrm{O}_{5}\right)$ fibres as tissue-engineering scaffolds by electrospinning. The authors fabricated a three-dimensional 
(3D) macro-structure with a $\sim 50-100 \mu \mathrm{m}$ interconnected macroporous structure by electrospinning, and the fibres were reported to possess a well-ordered hexagonal mesostructure with excellent in vitro bioactivity. Lu et al. [94] demonstrated submicron bioactive glass $\left(70 \mathrm{SiO}_{2} \cdot 30 \mathrm{CaO}\right)$ fibres for a bone tissue scaffold by electrospinning. The diameters of the submicron fibres were reported in the range of $50-800 \mathrm{~nm}$, and the hardness and elastic modulus of the fibres were measured by nano-indentation to be 0.21 and $5.5 \mathrm{GPa}$, respectively [94]. Allo et al. [95] fabricated composite nanofibres of PCL and tertiary bioactive glass (with a glass composition of $70 \mathrm{~mol} \% \mathrm{SiO}_{2}, 26 \mathrm{~mol} \% \mathrm{CaO}$ and $4 \mathrm{~mol} \%$ of $\mathrm{P}_{2} \mathrm{O}_{5}$ ) by electrospinning.

Figure 7. (a) TEM images of bioactive glass nanofibre after incubation in a simulated body fluid for three days [89] (reproduced with permission from Wiley, Copyright 2006); (b) TEM image of the bioactive glass nanofibre (BGNF)-Col nanocomposite, showing the mesoporous BGNF nanofibres (300-400 $\mathrm{nm}$ in diameter) organized with collagen self-assembled nano-fibrils (less than $100 \mathrm{~nm}$ in diameter) [90] (reproduced with permission from Wiley, Copyright 2006); and (c) fluorescence microscopy images showing the osteoblast precursor cell (MC3T3-E1) morphology after culturing for three days on electrospun bioactive glass fibres [96] (reproduced with permission from Elsevier, Copyright 2012).

(a)

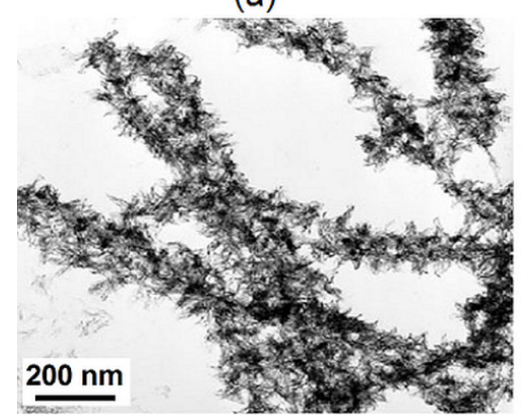

(b)

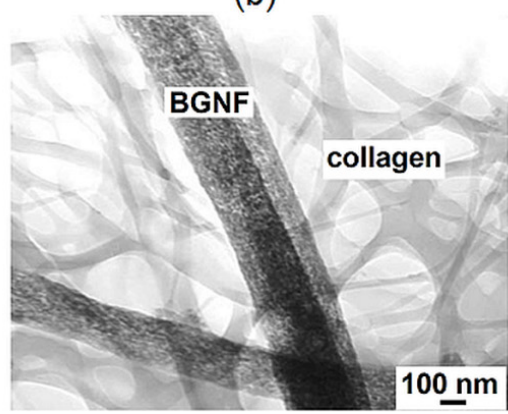

(c)

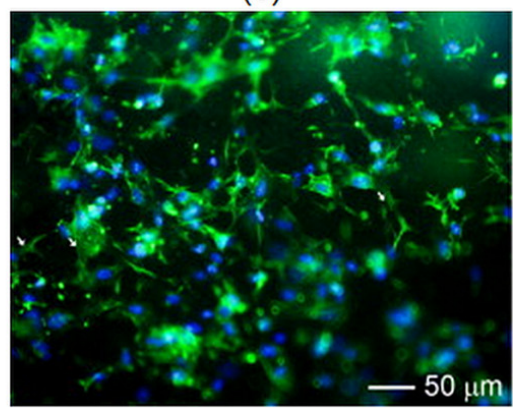

Boccaccini et al. [97] discussed the physico-chemical, mechanical and biological advantages of incorporating nanoscale bioactive glass in biodegradable nanocomposites and the possibilities to expand the use of these materials in other nanotechnology concepts aimed for use in different biomedical applications. Furthermore, Rahman et al. [98] assessed bioactive glasses in tissue engineering, reporting bioactive glass to have a unique set of properties, such as converting to an HA-like material, to bond firmly to hard and soft tissues and to release ions during the degradation process. These ions are also reported to have a beneficial effect on osteogenesis and on angiogenesis, which may also have a beneficial effect on chondrogenesis [98]. Interestingly, Xie et al. [96] fabricated submicron bioactive glass tubes using sol-gel and coaxial electrospinning techniques for applications in bone tissue engineering. The author also demonstrated that the proliferation rate of mouse preosteoblastic MC3T3-E1 cells on bioactive glass tubes (Figure 7c) was comparable to that on solid fibres, and the bioactive glass tubes can be loaded with a model protein drug, bovine serum albumin, where these structures exhibit delayed release properties. Recently, Huang et al. [99] fabricated luminescent $\mathrm{Eu}^{3+} / \mathrm{Tb}^{3+}$-doped mesoporous bioactive glass nanofibres (MBGNFs) with an average diameter of 100-120 $\mathrm{nm}$ by the electrospinning method. The author reported that the 
biocompatibility tests conducted with L929 fibroblast cells using the MTT assay revealed the low cytotoxicity of the generated nanofibres, whereas the luminescent nanofibres showed sustained release properties for ibuprofen (IBU) in vitro, and the emission intensities of $\mathrm{Eu}^{3+}$ in the drug delivery system varied with the released amount of IBU.

\section{Conclusion and Future Perspective}

Electrospinning is a simple and adaptable technique for high functional nanofibre production, which can amend the world of structural and functional materials. The advantages of the electrospinning technique, including the production of very thin fibres with a large surface area, aspect ratio, superior mechanical properties and ease of functionalization for various purposes, provide a wide range of opportunities for their application in tissue engineering, drug delivery, etc. Recently, composite electrospinning of nHAp-bioglass [100,101], PAN-bioglass [102,103] hybrids and ceramic-based composites containing new bioceramics, such as willemite $\left(\mathrm{Zn}_{2} \mathrm{SiO}_{4}\right)$ [104], dicalcium phosphate anhydrate (DCPA) [105], dicalcium silicate $\left(\mathrm{C}_{2} \mathrm{~S}\right)$ [106], etc., has demonstrated these as potential candidates for bone tissue regeneration, showing the advancements in the field.

Synthetic HAp, being extensively used in hard tissue regeneration, like bone, can be potentially substituted or replaced by HAp derived from natural sources, like eggshell, corals, etc. [107,108], which could mimic ions close to that of natural bone, leading to better biocompatibility and tissue interactions. Furthermore, the use of CNT to reinforce and enhance the performance of the composite can produce a new generation of nanocomposite materials, where the critical issues of CNT embedment in nanocomposites during processing have to be studied in detail. Moreover, the surface modification of electrospun scaffolds with suitable bioactive agents could be an effective means to fine-tune the functionality of nanofibres for specific biomedical applications.

\section{Authors Contributions}

Rajkamal Balu wrote and edited the manuscript. All authors suggested improvements and agree with the final manuscript.

\section{Conflicts of Interest}

The authors declare no conflict of interest.

\section{References}

1. Hench, L.L.; Wilson, J. An Introduction to Bioceramics; Advance Series in Bioceramics, 1st ed.; World Scientific Publishing: Singapore, 1993.

2. Thamaraiselvi, T.V.; Rajeswari, S. Biological evaluation of bioceramic materials-A review. Trends Biomater. Artif. Organs 2004, 18, 9-17.

3. Ramaseshan, R.; Ramakrishna, S.; Sundarrajan, S.; Jose, R. Nanostructured ceramics by electrospinning. J. Appl. Phys. 2007, 102, 111101.

4. Xiong, C.; Kim, M.J.; Balkus, K.J. $\mathrm{TiO}_{2}$ nanofibres and core-shell structures prepared using mesoporous molecular sieves as templates. Small 2006, 2, 52-55. 
5. Lak, A.; Mazloumi, M.; Mohajerani, M.; Kajbafvala, A.; Zanganeh, S.; Arami, H.; Sadrnezhaad, S.K. Self-assembly of dandelion-like hydroxyapatite nanostructures via hydrothermal method. J. Am. Ceram. Soc. 2008, 91, 3292-3297.

6. Li, D.; Xia, Y. Fabrication of titania nanofibers by electrospinning. Nano Lett. 2003, 3, 555-560.

7. Ramakrishna, S.; Fugihara, K.; Teo, W.E.; Lim, T.C.; Ma, Z. An Introduction to Electrospinning and Nanofibres; World Scientific Publishing: Singapore, 2005.

8. Vendorf, J.H.; Agarwal, S.; Greiner, A. Electrospinning: Material Processing and Applications; John Wiley \& Sons: Weinheim, Germany, 2012.

9. Taylor, G. Electrically driven jets. Proc. R. Soc. London Ser. A 1969, 313, 453-475.

10. Yarin, A.L.; Koombhongse, S. Taylor cone and jetting from liquid droplets in electrospinning of nanofibers. J. Appl. Phys. 2001, 90, 4836-4846.

11. Li, D.; Xia, Y.N. Electrospinning of nanofibers: Reinventing the wheel. Adv. Mater. 2004, 16, 1151-1170.

12. Frenot, A.; Chronakis, L.S. Polymer nanofibres assembled by electrospinning. Curr. Opin. Colloid Interface Sci. 2003, 8, 64-75.

13. Huang, Z.M.; Zhang, Y.Z.; Kotaki, M.; Ramakrishna, S. A review on polymer nanofibers by electrospinning and their applications in nanocomposites. Compos. Sci. Technol. 2003, 63, 2223-2253.

14. Liang, D.; Hsiao, B.S. Functional electrospun nanofibrous scaffolds for biomedical applications. Adv. Drug Deliv. Rev. 2007, 59, 1392-1412.

15. Son, W.K.; Cho, D. Direct electrospinning of ultrafine titania fibres in the absence of polymer additives and formation of pure anatase titania fibres at low temperature. Nanotechnology 2006, 17, 439-443.

16. Wang, Y.; Aviles, J.J.S. Synthesis of lead zirconate titanate nanofibres and the Fourier-transform infrared characterization of their metallo-organic decomposition process. Nanotechnology 2004, $15,32-36$.

17. Yuh, J.; Perez, L.; Sigmund, W.M.; Nino, J.C. Sol-gel based synthesis of complex oxide nanofibers. J. Sol-Gel Sci. Technol. 2007, 42, 323-329.

18. Boutin, P.; Blanquaert, D. A study of the mechanical properties of alumina-on-alumina total hip prosthesis. Rev. Chir. Orthop. Reparatrice Appar. Mot. 1981, 67, 279-287.

19. Price, R.L.; Haberstroh, K.M.; Webster, T.J. Enhanced functions of osteoblasts on nanostructured surfaces of carbon and alumina. Med. Biol. Eng. Comput. 2003, 41, 372-375.

20. Azad, A.M. Fabrication of transparent alumina $\left(\mathrm{Al}_{2} \mathrm{O}_{3}\right)$ nanofibers by electrospinning. Mater. Sci. Eng. A 2006, 435, 468-473.

21. Panda, P.K.; Ramakrishna, S. Electrospinning of alumina nanofibers using different precursors. J. Mater. Sci. 2007, 42, 2189-2193.

22. Tuttle, R.W.; Chowdury, A.; Bender, E.T.; Ramsier, R.D.; Rapp, J.L.; Espe, M.P. Electrospun ceramic fibers: Composition, structure and the fate of precursors. Appl. Surf. Sci. 2008, 254, 4925-4929.

23. Lamastra, F.R.; Bianco, A.; Meriggi, A.; Montesperelli, G.; Nanni, F.; Gusmano, G. Nanohybrid $\mathrm{PVA} / \mathrm{ZrO}_{2}$ and $\mathrm{PVA} / \mathrm{Al}_{2} \mathrm{O}_{3}$ electrospun mats. Chem. Eng. J. 2008, 145, 169-175. 
24. Yu, P.C.; Yang, R.J.; Tsai, Y.Y.; Sigmund, W.; Yen, F.S. Growth mechanism of single-crystal $\alpha-\mathrm{Al}_{2} \mathrm{O}_{3}$ nanofibers fabricated by electrospinning techniques. J. Eur. Ceram. Soc. 2011, 31, $723-731$.

25. Yu, H.; Guo, J.; Zhu, S.; Li, Y.; Zhang, Q.; Zhu, M. Preparation of continuous alumina nanofibers via electrospinning of PAN/DMF solution. Mater. Lett. 2012, 74, 247-249.

26. Price, R.L.; Gutwein, L.G.; Kaledin, L.; Tepper, F.; Webster, T.J. Osteoblast function on nanophase alumina materials: Influence of chemistry, phase, and topography. J. Biomed. Mater. Res. Part A 2003, 67, 1284-1293.

27. Scarano, A.; Carlo, F.D.; Quaranta, M.; Piattelli, A. Bone response to zirconia ceramic implants: An experimental study in rabbits. J. Oral Implant. 2003, 29, 8-12.

28. Shao, C.; Guan, H.; Liu, Y.; Gong, J.; Yu, N.; Yang, X. A novel method for making $\mathrm{ZrO}_{2}$ nanofibres via an electrospinning technique. J. Cryst. Growth 2004, 267, 380-384.

29. Dharmaraj, N.; Kim, C.; Kim, H. Synthesis and characterisation of zirconium oxide nanofibers by electrospinning. Synth. React. Inorg. Met.-Org. Nano-Met. Chem. 2006, 36, 29-32.

30. Davidson, J.A. Zirconium oxide and zirconium nitride coated biocompatible leads. US Patent 5496359, 5 March 1995.

31. Li, J.Y.; Sun, Y.; Tan, Y.; Xu, F.M.; Shi, X.L.; Ren, N. Zirconium nitride (ZrN) fibers prepared by carbothermal reduction and nitridation of electrospun PVP/zirconium oxychloride composite fibers. Chem. Eng. J. 2008, 144, 149-152.

32. Ahmad, I. Yttrium-partially stabilized zirconium dioxide posts: An approach to restoring coronally compromised nonvital teeth. Int. J. Periodont. Restor. Dent. 1998, 18, 455-465.

33. Azad, A.M. Fabrication of yttria-stabilized zirconia nanofibers by electrospinning. Mater. Lett. 2006, 60, 67-72.

34. Li, J.Y.; Tan, Y.; Xu, F.M.; Sun, Y.; Cao, X.Q.; Zhang, Y.F. Hollow fibers of yttria-stabilized zirconia (8YSZ) prepared by calcination of electrospun composite fibers. Mater. Lett. 2008, 62, 2396-2399.

35. Kotha, S.; Li, C.; Schmid, S.; Mason, J. Reinforcement of bone cement using zirconia fibers with and without acrylic coating. J. Biomed. Mater. Res. Part A 2009, 88, 898-906.

36. Li, L.; Zhang, P.; Liang, J.; Guo, S.M. Phase transformation and morphological evolution of electrospun zirconia nanofibers during thermal annealing. Ceram. Int. 2010, 36, 589-594.

37. Qin, D.; Gu, A.; Liang, G.; Yuan, L. A facile method to prepare zirconia electrospun fibers with different morphologies and their novel composites based on cyanate ester resin. RSC $A d v . \mathbf{2 0 1 2}$, 2, 1364-1372.

38. Xu, X.; Guo, G.; Fan, Y. Fabrication and characterization of dense zirconia and zirconia-silica ceramic nanofibers. J. Nanosci. Nanotechnol. 2010, 10, 5672-5679.

39. Hayashi, K.; Matsuguchi, N.; Uenoyama, K.; Kanemaru, T.; Sugioka, Y. Evaluation of metal implants coated with several types of ceramics as biomaterials. J. Biomed. Mater. Res. Part A 1989, 23, 1247-1259.

40. Cui, C.; Liu, H.; Li, Y.; Sun, J.; Wang, R.; Liu, S.; Greer, A.L. Fabrication and biocompatibility of nano- $\mathrm{TiO}_{2} /$ titanium alloys biomaterials. Mater. Lett. 2005, 59, 3144-3148.

41. Lee, S.H.; Tekmen, C.; Sigmund, W.M. Three-point bending of electrospun $\mathrm{TiO}_{2}$ nanofibers. Mater. Sci. Eng. A 2005, 398, 77-81. 
42. Lim, J.I.; Yu, B.; Woo, K.M.; Lee, Y.K. Immobilization of $\mathrm{TiO}_{2}$ nanofibers on titanium plates for implant applications. Appl. Surf. Sci. 2008, 255, 2456-2460.

43. Yuh, J.; Nino, J.C.; Sigmund, W.M. Synthesis of barium titanate $\left(\mathrm{BaTiO}_{3}\right)$ nanofibers via electrospinning. Mater. Lett. 2005, 59, 3645-3647.

44. Li, Z.; Qu, Y.; Zhang, X.; Yang, B. Bioactive nano-titania ceramics with biomechanical compatibility prepared by doping with piezoelectric $\mathrm{BaTiO}_{3}$. Acta Biomater. 2009, 5, 2189-2195.

45. Young-taek, S. Osseoinductive magnesium-titanate implant and method of manufacturing the same. US Patent 7452566, 15 September 2005.

46. Dharmaraj, N.; Park, H.C.; Lee, B.M.; Viswanathamurthi, P.; Kim, H.Y.; Lee, D.R. Preparation and morphology of magnesium titanate nanofibres via electrospinning. Inorg. Chem. Commun. 2004, 7, 431-433.

47. Lee, S.W.; Kim, Y.U.; Choi, S.S.; Park, T.Y.; Joo, Y.L.; Lee, S.G. Preparation of $\mathrm{SiO}_{2} / \mathrm{TiO}_{2}$ composite fibers by sol-gel reaction and electrospinning. Mater. Lett. 2007, 61, 889-893.

48. Fahim, N.F.; Morks, M.F.; Sekino, T. Electrochemical synthesis of silica-doped high aspect-ratio titania nanotubes as nanobioceramics for implant applications. Electrochim. Acta 2009, 54, 3255-3269.

49. Darmaraj, N.; Park, H.C.; Kim, C.K.; Kim, H.Y.; Lee, D.R. Nickel titanate nanofibers by electrospinning. Mater. Chem. Phys. 2004, 87, 5-9.

50. Bansiddhi, A.; Sargeant, T.D.; Stupp, S.I.; Dunand, D.C. Porous NiTi for bone implants: A review. Acta Biomater. 2008, 4, 773-782.

51. Bahadur, K.C.R.; Kim, C.K.; Khil, M.S.; Kim, H.Y.; Kim, I.S. Synthesis of hydroxyapatite crystals using titanium oxide electrospun nanofibers. Mater. Sci. Eng. C 2008, 28, 70-74.

52. Amna, T.; Hassan, M.S.; Barakat, N.A.M.; Pandeya, D.R.; Hong, S.T.; Khil, M.S.; Kim, H.Y. Antibacterial activity and interaction mechanism of electrospun zinc-doped titania nanofibers. Appl. Microbiol. Biotechnol. 2012, 93, 743-751.

53. Hassan, M.S.; Amna, T.; Mishra, A.; Yun, S.I.; Kim, H.C.; Kim, H.Y.; Khil, M.S. Fabrication, characterization and antibacterial effect of novel electrospun $\mathrm{TiO}_{2}$ nanorods on a panel of pathogenic bacteria. J. Biomed. Nanotechnol. 2012, 8, 394-404.

54. Wang, X.; Zhu, J.; Yin, L.; Liu, S.; Zhang, X.; Ao, Y.; Chen, H. Evaluation of the morphology and osteogenic potential of titania-based electrospun nanofibers. J. Nanomater. 2012, 2012, 1-7.

55. Kiran, A.S.K.; Balu, R.; Kumar, T.S.S.J. Vero cell viability and human osteoblast cell response to electrospun phase controlled titania nanofibers. J. Biomater. Tissue Eng. 2012, 2, 292-298.

56. Sundarajan, V.M. Principles of Biomedical Engineering; Artech House: London, UK, 2010.

57. Santiago-Aviles, J.J.; Wang, Y. Magnetoconductance, carrier concentration and mobility measurement in electrospun carbon nanofibers. Carbon 2003, 41, 2665-2667.

58. Zimmerman, M.; Parsons, J.R.; Alexander, H.; Weiss, A.B. The electrical stimulation of bone using a filamentous carbon cathode. J. Biomed. Mat. Res. Part A 2004, 18, 927-938.

59. Zussman, E.; Chen, X.; Ding, W.; Calabri, L.; Dikin, D.A.; Quintana, J.P.; Ruoff, R.S. Mechanical and structural characterization of electrospun PAN-derived carbon nanofibers. Carbon 2005, 43, 2175-2185. 
60. Gomes, D.S.; Silva, A.N.R.; Morimoto, N.I.; Mendes, L.T.F.; Furlan, R.; Ramos, I. Characterization of an electrospinning process using different PAN/DMF concentrations. Polim. Cienc. Tecnol. 2007, 17, 206-211.

61. Kim, C.; Cho, Y.J.; Yun, W.Y.; Ngoc, B.T.N.; Yang, K.S.; Chang, D.R.; Lee, J.W.; Kojima, M.; Kim, Y.A.; Endo, M. Fabrications and structural characterization of ultra-fine carbon fibres by electrospinning of polymer blends. Solid State Commun. 2007, 142, 20-23.

62. Ko, F.; Gogotsi, Y.; Ali, A.; Naguib, N.; Ye, H.; Yang, G.L.; Li, C.; Willis, P. Electrospinning of continuous carbon nanotube-filled nanofibers yarns. Adv. Mater. 2003, 15, 1161-1165.

63. Correa-Duarte, M.A.; Wagner, N.; Rojas-Chapana, J.; Morsczeck, C.; Michael Thie, M.; Giersig, M. Fabrication and biocompatibility of carbon nanotube-based 3D networks as scaffolds for cell seeding and growth. Nano Lett. 2004, 4, 2233-2236.

64. Lam, H.; Titchenal, N.; Naguib, N.; Ye, H.; Gogotsi, Y.; Ko, F. Electrospinning of carbon nanotube reinforced nanocomposite fibrils and yarns. Mater. Res. Soc. Symp. Proc. 2003, 791, doi: 10.1557/PROC-791-Q10.5.

65. Smart, S.K.; Cassady, A.I.; Lu, G.Q.; Martin, D.J. The biocompatibility of carbon nanotubes. Carbon 2006, 44, 1034-1047.

66. Yeo, L.Y.; Friend, J.R. Electrospinning carbon nanotube polymer composite nanofibers. J. Exp. Nanosci. 2006, 1, 177-209.

67. Zhang, Q.; Chang, Z.; Zhu, M.; Mo, X.; Chen, D. Electrospun carbon nanotube composite nanofibers with uniaxially aligned arrays. Nanotechnology 2007, 18, 115611.

68. Wan, Y.Q.; He, J.H.; Yu, J.Y. Carbon nanotube-reinforced polyacrylonitrile nanofibres by vibration-electrospinning. Polym. Int. 2007, 56, 1367-1370.

69. Tran, P.A.; Zhang, L.; Webster, T.J. Carbon nanofibers and carbon nanotubes in regenerative medicine. Adv. Drug Deliv. Rev. 2009, 61, 1097-1114.

70. Tavangarian, F.; Li, Y. Carbon nanostructures as nerve scaffolds for repairing large gaps in severed nerves. Ceram. Int. 2012, 38, 6075-6090.

71. Volpato, F.Z.; Ramos, S.L.F.; Motta, A.; Migliaresi, C. Physical and in vitro biological evaluation of a PA 6/MWCNT electrospun composite for biomedical applications. J. Bioact. Compat. Polym. 2011, 26, 35-47.

72. Ito, Y.; Hasuda, H.; Kamitakahara, M.; Ohtsuki, C.; Tanihara, M.; Kang, I.K.; Kwon, O.H. A composite of hydroxyapatite with electrospun biodegradable nanofibres as a tissue engineering material. J. Biosci. Bioeng. 2005, 100, 43-49.

73. Venugopal, J.; Vadgama, P.; Kumar, T.S.S.; Ramakrishna, S. Biocomposite nanofibres and osteoblasts for bone tissue engineering. Nanotechnology 2007, 18, 55101.

74. Ding, Y.M.; Yuan, X.Y.; Zhao, J.; Guo, W.C.; Wang, X.K. Formation of ultrafine apatite fibres by sol-gel/electrospinning. Chem. Res. Chin. Univ. 2007, 23, 366-369.

75. Li, X.; Yao, C.; Sun, F.; Song, T.; Li, Y.; Pu, Y. Conjugate electrospinning of continuous nanofibre yarn of poly(L-lactide)/nanotricalcium phosphate nanocomposite. J. Appl. Polym. Sci. 2008, 107, 3756-3764.

76. Erisken, C.; Kalyon, D.M.; Wang, H. Functionally graded electrospun polycaprolactone and $\beta$-tricalcium phosphate nanocomposites for tissue engineering applications. Biomaterials 2008, $29,4065-4073$. 
77. Teng, S.H.; Lee, E.J.; Wang, P.; Kim, H.E. Collagen/hydroxyapatite composite nanofibres by electrospinning. Mater. Lett. 2008, 62, 3055-3058.

78. Guan, D.; Chen, Z.; Huang, C.; Lin, Y. Attachment, proliferation and differentiation of BMSCs on gas-jet/electrospun nHAP/PHB fibrous scaffolds. Appl. Surf. Sci. 2008, 255, 324-327.

79. Zhang, Y.; Venugopal, J.R.; El-Turki, A.; Ramakrishna, S.; Su, B.; Lim, C.T. Electrospun biomimetic nanocomposite nanofibers of hydroxyapatite/chitosan for bone tissue engineering. Biomaterials 2008, 29, 4314-4322.

80. Liao, S.; Murugan, R.; Chan, C.K.; Ramakrishna, S. Processing nanoengineered scaffolds through electrospinning and mineralization suitable for biomimetic bone tissue engineering. J. Mech. Behav. Biomed. Mater. 2008, 1, 252-260.

81. Yang, F.; Wolke, J.G.C.; Jansen, J.A. Biomimetic calcium phosphate coating on electrospun poly(E-caprolactone) scaffolds for bone tissue engineering. Chem. Eng. J. 2008, 137, 154-161.

82. Chen, F.; Tang, Q.L.; Zhu, Y.J.; Wang, K.W.; Zhang, M.L.; Zhai, W.Y.; Chang, J. Hydroxyapatite nanorods/poly(vinyl pyrolidone) composite nanofibres, arrays and three-dimensional fabrics: Electrospun preparation and transformation to hydroxyapatite nanostructures. Acta Biomater. 2010, 6, 3013-3020.

83. Yu, H.S.; Hong, S.J.; Kim, H.W. Surface-mineralized polymeric nanofiber for the population and osteogenic stimulation of rat bone-marrow stromal cells. Mater. Chem. Phys. 2009, 113, 873-877.

84. Jose, M.V.; Thomas, V.; Johnson, K.T.; Dean, D.R.; Nyairo, E. Aligned PLGA/HA nanofibrous nanocomposite scaffolds for bone tissue engineering. Acta Biomater. 2009, 5, 305-315.

85. Ye, H.; Liu, X.Y.; Hong, H. Cladding of titanium/hydroxyapatite composites onto Ti6Al4V for load-bearing implant applications. Mater. Sci. Eng. C 2009, 29, 2063-2044.

86. Wei, K.; Li, Y.; Kim, K.O.; Nakagawa, Y.; Kim, B.S.; Abe, K.; Chen, G.Q.; Kim, I.S. Fabrication of nano-hydroxyapatite on electrospun silk fibroin nanofibre and their effects in osteoblastic behavior. J. Biomed. Mater. Res. Part A 2011, 97, 272-280.

87. Song, X.; Ling, F.; Li, H.; Gao, Z.; Chen, X. Tuned morphological electrospun hydroxyapatite nanofibres via pH. J. Bionic Eng. 2012, 9, 478-483.

88. Hench, L.L. The story of bioglass. J. Mater. Sci. Mater. Med. 2006, 17, 967-978.

89. Kim, H.W.; Kim, H.E.; Knowles, J.C. Production and potential of bioactive glass nanofibres as a next-generation biomaterial. Adv. Funct. Mater 2006, 16, 1529-1535.

90. Kim, H.W.; Song, J.H.; Kim, H.E. Bioactive glass nanofibre-collagen nanocomposite as a novel bone regeneration matrix. J. Biomed. Mater. Res. Part A 2006, 79, 698-705.

91. Kim, H.W.; Lee, H.H.; Chun, G.S. Bioactivity and osteoblast responses of novel biomedical nanocomposites of bioactive glass nanofibre filled poly(lactic acid). J. Biomed. Mater. Res. Part A 2008, 85, 651-663.

92. Lee, H.H.; Yu, H.S.; Jang, J.H.; Kim, H.W. Bioactivity improvement of poly(e-caprolactone) membrane with the addition of nanofibrous bioactive glass. Acta Biomater. 2008, 4, 622-629.

93. Yi, J.; Wei, G.; Huang, X.; Zhao, L.; Zhang, Q.; Yu, C. Sol-gel derived mesoporous bioactive glass fibres as tissue-engineering scaffolds. J. Sol-Gel Sci. Technol. 2008, 45, 115-119.

94. Lu, H.; Zhang, T.; Wang, X.P.; Fang, Q.F. Electrospun submicron bioactive glass fibres for bone tissue scaffold. J. Mater. Sci. Mater. Med. 2009, 20, 793-798. 
95. Allo, B.A.; Rizkalla, A.S.; Mequanint, K. Synthesis and electrospinning of $\varepsilon$-polycaprolactonebioactive glass hybrid biomaterials via a sol-gel process. Langmuir 2010, 26, 18340-18348.

96. Xie, J.; Blough, E.R.; Wang, C.H. Submicron bioactive glass tubes for bone tissue engineering. Acta Biomater. 2012, 8, 811-819.

97. Boccaccini, A.R.; Erol, M.; Stark, W.J.; Mohn, D.; Hong, Z.; Mano, J.F. Polymer/Bioactive glass nanocomposites for biomedical applications: A review. Compos. Sci. Technol. 2010, 70, 1764-1776.

98. Rahaman, M.N.; Day, D.E.; Bal, B.S.; Fu, Q.; Jung, S.B.; Bonewald, L.F.; Tomsia, A.P. Bioactive glass in tissue engineering. Acta Biomater. 2011, 7, 2355-2373.

99. Huang, S.; Kang, X.; Cheng, Z.; Ma, P.; Jia, Y.; Lin, J. Electrospinning preparation and drug delivery properties of $\mathrm{Eu}^{3+} / \mathrm{Tb}^{3+}$ doped mesoporous bioactive glass nanofibres. J. Colloid Interface Sci. 2012, 387, 285-291.

100. Tan, C.; Hong, Y.; Zhang, X. Hydroxyapatite nanoparticle-strengthened bioactive glass nanofibres. Micro Nano Lett. 2013, 8, 470-472.

101. Shalumon, K.T.; Sowmya, S.; Sathish, D.; Chennazhi, K.P.; Nair, S.V.; Jayakumar, R. Effect of incorporation of nanoscale bioactive glass and hydroxyapatite in PCL/chitosan nanofibres for bone and periodontal tissue engineering. J. Biomed. Nanotechnol. 2013, 9, 430-440.

102. Yang, Q.; Sui, G.; Shi, Y.Z.; Duan, S.; Bao, J.Q.; Cai, Q.; Yang, X.P. Osteocompatibility characterization of polyacrylonitrile carbon nanofibres containing bioactive glass nanoparticles. Carbon 2013, 56, 288-295.

103. Han, B.; Zhang, X.; Liu, H.; Deng, X.; Cai, Q.; Jia, X.; Yang, X.; Wei, Y.; Li, G. Improved bioactivity of PAN-based carbon nanofibres decorated with bioglass nanoparticles. J. Biomater. Sci. Polym. Ed. 2014, 25, 341-353.

104. Adegani, F.J.; Langroudi, L.; Ardeshirylajimi, A.; Dinarvand, P.; Dodel, M.; Doostmohammadi, A.; Rahimian, A.; Zohrabi, P.; Seyedjafari, E.; Soleimani, M. Coating of electrospun poly(lactic-co-glycolic acid) nanofibres with willemite bioceramic: Improvement of bone reconstruction in rat model. Cell Biol. Int. 2014, 2014, doi: 10.1002/cbin.10318.

105. Chae, T.; Yang, H.; Ko, F.; Troczynski, T. Bio-inspired dicalcium phosphate anhydrate/poly(lactic acid) nanocomposite fibrous scaffolds for hard tissue regeneration: In situ synthesis and electrospinning. J. Biomed. Mater. Res. Part A 2013, 102, 514-522.

106. Dong, S.; Suna, J.; Li, Y.; Li, J.; Cui, W.; Li, B. Electrospun nanofibrous scaffolds of poly (L-lactic acid)-dicalcium silicate composite via ultrasonic-aging technique for bone regeneration. Mater. Sci. Eng. C 2014, 35, 426-433.

107. Manjubala, I.; Sivakumar, M.; Kumar, T.S.S.; Rao, K.P. Synthesis and characterization of functional gradient materials using indian corals. J. Mater. Sci. Mater. Med. 2000, 11, 705-709.

108. Krishna, D.S.R.; Siddharthan, A.; Seshadri, S.K.; Kumar, T.S.S. Nanocrystalline hydroxyapatite from eggshell waste by microwave processing and its sintering studies. J. Mater. Sci. Mater. Med. 2007, 18, 1735-1743.

(C) 2014 by the authors; licensee MDPI, Basel, Switzerland. This article is an open access article distributed under the terms and conditions of the Creative Commons Attribution license (http://creativecommons.org/licenses/by/3.0/). 